\title{
Can we import improvements from industry to healthcare?
}

\section{Healthcare has more to learn from other industries, including aviation-but it's more complex than we think argue Carl Macrae and Kevin Stewart}

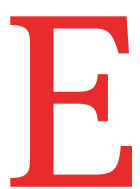
xhortations to learn from other industries have been common in the world of healthcare improvement since the inception of the discipline. ${ }^{1}$ These are not always helpful. Recounting oversimplified improvement examples from other industries (often aviation) can provoke considerable frustration and scepticism among clinicians exposed to the unique challenges and everyday complexities of trying to improve healthcare. Patients are not aeroplanes, and hospitals are not production lines. Nonetheless, many successful efforts to improve the quality and safety of healthcare have taken inspiration from other industries. Here we re-examine some familiar exemplars from the aviation industry to show what is (still) to be learnt, even in areas that have made substantial improvements.

\section{No simple solution}

From simulation training ${ }^{2}$ to patient handover $^{3}$ to structured communication ${ }^{4}$ to quality improvement itself, ${ }^{5}$ many healthcare improvement interventions have been adapted from industrial settings as diverse as civil aviation, nuclear power, and car

\section{KEY MESSAGES}

- Many of the improvement strategies, tools, and techniques in healthcare have been drawn from other industries

- When transferring improvement methods key elements are often missed, mistranslated, or inappropriate to healthcare

- It is important to understand the work context and organisational systems that underpin a method's success

- Better understanding of healthcare systems is also vital for successful translation

- Other industries allocate considerable resources and dedicated staff to systems analysis and quality improvement manufacturing. Initially, learning from other industries seems to offer a simple shortcut to anyone trying to improve healthcare. Other industries have spent decades developing tools, methods, strategies, and techniques to improve quality and safety: why not just apply these in healthcare?

Of course, it is not that simple. Translating and adapting improvement techniques to healthcare is hard and has had varied results. Some interventions, such as those aimed at reducing infections related to central venous catheters, have proved popular and successful ${ }^{6}$; others, such as incident reporting systems, have met with frustration and failure. ${ }^{7}$ Initial enthusiasm for oversimplified, large scale attempts to apply a new improvement technique often quickly gives way to confusion, complication, and criticism. ${ }^{89}$

Despite these difficulties and frustrations, looking to other industries for ideas and inspiration still has value, just as other industries are increasingly looking to learn from healthcare. ${ }^{10}$ But to do this well requires a more sophisticated approach centred on three principles.

Firstly, efforts to translate improvement strategies from one setting to another need to be based on a sophisticated understanding of the contextual, practical, and structural differences (and similarities) between those settings. ${ }^{11}$ Secondly, translational efforts need to pay close attention to the cultural and organisational arrangements that support the particular improvement intervention. Thirdly, any translational effort needs to be based on a process of careful adaptation and intelligent reinvention, not simply importing and applying a readymade tool.

\section{Lost in translation}

Why is learning from other industries so hard? One of the main reasons is obvious: caring for patients is radically different from making cars or flying aeroplanes. Healthcare is unique in the intimacy, complexity, and sensitivity of the services it provides as well as the trust, compassion, and empathy that underpin it. ${ }^{12}$ Healthcare is also enormously varied: elective surgery, community mental health, emergency medicine, and palliative care are very different in terms of the work, knowledge, and activities involved-and the ways they need to be organised and managed.

Healthcare is better understood as perhaps 20 different industries, many of which need to seamlessly interact at critical junctures throughout a patient's journey. ${ }^{13}$ What works in one part of healthcare may not work in another. It is therefore unsurprising that what works in an entirely different industry, such as car manufacturing, may not easily and directly transfer to all healthcare settings. The diversity of healthcare means that it is almost meaningless to compare it with nuclear power or aviation.

Another rarely recognised consideration is that work in other industries is also diverse. In the healthcare literature, for example, "aviation" is often translated as "pilots flying aeroplanes"14_which overlooks the considerable differences between the operational work of flight crew, the diagnostic work of engineers, the physical repair work of maintenance technicians, the design work of system analysts, and the myriad other activities that constitute any complex industry.

When attempting to transfer improvement lessons, it is important to understand the precise nature of the work in different healthcare settings as well as in other industries. For instance, it might be useful to draw parallels between the technical, process oriented, monitoring activities of anaesthesia and similar types of activities in the control rooms of nuclear power plants. ${ }^{10}$ Likewise, the complex diagnostic tasks, multiple handovers, and relatively isolated working patterns of maintenance engineering may be a useful analogue for some elements of primary care.

In addition, successful translation from other industries into healthcare typically depends on considerable adaptation and reinvention of the original improvement techniques. This can be seen in three areas 
of healthcare improvement that have drawn heavily on techniques pioneered in other industries.

\section{Incident investigation and analysis}

Analysing and investigating adverse incidents has been a cornerstone of improving patient safety for many years. The pioneering reports that established the discipline drew directly on the experience of other industries, primarily aviation, ${ }^{15}{ }^{16}$ and incident reporting systems have subsequently become one of the most widely implemented improvement strategies across modern healthcare. The English National Reporting and Learning System currently collects data on over two million incident reports each year ${ }^{17}$ and root cause analysis techniques have been widely adopted. ${ }^{8}$

However, the translation of these approaches into healthcare has often missed or misconstrued some of the most important elements seen in other industries. Incident investigations in industries such as nuclear power ${ }^{18}$ are typically conducted by dedicated in-house teams of professionally trained investigators; routinely incorporate rigorous human factors and systems analysis; are separated entirely from any management processes that seek to allocate blame; and typically produce actions that focus on strong, systemic safety improvements such as redesigning equipment.

In contrast, the fundamental organisational systems and structures needed to effectively learn from incident investigations remain relatively underdeveloped in many healthcare settings. Investigations can get tangled up with political processes of blame, there is limited expertise, and resulting improvement actions are not always robust. ${ }^{8}$ There has also been a heavy focus on collecting and recording large quantities of incidents. Reporting incidents has almost become an end in itself, whereas in other industries incidents are used merely as a starting point to investigate and improve work systems. ${ }^{19}$

Growing frustration ${ }^{7}$ has recently led to a reappraisal of the focus on reporting, with attention increasingly shifting back to the practical work of investigating and improving healthcare. ${ }^{2021}$ Notably, several national healthcare systems are developing the capacity for routine, system-wide safety investigations (box 1).

Many healthcare organisations still have a long way to go before they can reliably transform incidents into improvements.
Revisiting the organisational and cultural principles that support this in other industries still offers salient lessons, primarily the need for well resourced safety teams led by experts that allow systematic examination of practical work and the development of robust system level improvements in contexts removed from fear and blame. ${ }^{24}$

\section{Checklists and cognitive aids}

One of the highest profile improvement interventions adopted from other industries are safety checklists ${ }^{25}$ and other cognitive aids such as emergency manuals. ${ }^{26}$ Checklists provide a set of structured and practical instructions that either prompt, or serve to verify, a series of actions at key stages of a healthcare process-such as the sign-in process before surgery ${ }^{9}$ or during an anaesthetic emergency. ${ }^{26}$ Checklists draw directly on those used in other industries-aviation

in particular-and the approach has been widely popularised.

However, in the process of being imported into healthcare, checklists have taken on several functions beyond those in other industries. For example, in healthcare checklists are often intended to prompt communication and facilitate team functioning. In other industries, the collective use of checklists depends on the prior creation of cohesive and well functioning teams through building stable cultural norms and expectations, routinely training for simulated emergencies, and establishing standard protocols for reliable communication, ${ }^{326}$ rather than aiming to create effective teams through the use of a checklist.'

In other industries, checklists are just one element of a carefully designed sociotechnical system built to support processes for high reliability and effective

\section{Box 1: System-wide, learning focused, safety investigation}

\section{What?}

In April 2017 England became the first country to establish a dedicated, system-wide safety investigation organisation for healthcare: the Healthcare Safety Investigation Branch. Norway is launching a similar organisation in 2019 (the National Investigation Board for the Health and Care Services), and other countries are exploring the idea. ${ }^{22}$

Why?

The objectives of these new organisations are translated directly from other industries, including railways, shipping, and aviation: to undertake rigorous, non-punitive, and systematic investigations into serious patient safety risks that span the healthcare system to develop system-wide recommendations for learning and improvement. ${ }^{21}$

How?

Uniquely, the organisations are independent of all other parts of the healthcare system. They can therefore investigate and issue recommendations to all parts of the healthcare systemfrom frontline practice, to the design of equipment, to the regulation of services. Importantly, the investigation processes are focused solely on learning and are entirely separate from systems that seek to allocate blame, liability, or punishment. Information collected for the purposes of safety investigation will be used only for safety improvement and cannot be used by other organisations for punitive purposes. Ensuring this independence requires strong legislative protections to prevent safety information from being used inappropriately. ${ }^{23}$

What's different in healthcare?

The principles of investigation are common across all industries, but the practical specifics will need to be reinvented to deal with the unique challenges of healthcare. In particular:

- Healthcare practices draw on cutting edge and ever changing medical science and so investigations will need to engage with scientific evidence and will probably need to regularly recommend further scientific inquiry

- Health systems are much more complex than any transport industry and encompass a wide range of highly specialised professional groups, skilled activities, and advanced technologies

- Healthcare investigations must sensitively engage patients and families throughout the process; they are often the only people who see the entire trajectory of care

- Healthcare organisations routinely capture few data relevant to safety-there are no "black box" flight data recorders as in aviation-and the data that are collected may be difficult to collate and are often qualitative

- Healthcare processes are less specified and less standardised than in other industries, meaning there may be few benchmarks against which to identify deviation 
human performance. Some areas of healthcare, such as maternity care, have emulated this successfully. ${ }^{27}$ But in many healthcare settings the checklist may be the only element of an entire process that has been actively designed with reliability and safety in mind. ${ }^{9}$ This brings both risks and opportunities. One risk is that an over-reliance on checklists, coupled with unrealistic expectations regarding their application, leads to well meaning people with limited expertise developing cognitive aids that are poorly designed or ineffective and therefore distract more than they support.

Healthcare could learn further from the strategic use of cognitive aids and checklists as part of more integrated approaches to designing processes and improving reliability. For instance, considerable effort goes into supporting in-the-moment professional decision making by mapping out the complex conditions under which it is safe for an aircraft to depart and when it is not (box 2).

\section{Quality improvement and systems design}

Healthcare quality improvement owes its existence to other industries. Process reengineering and systems improvement tools such as lean production, ${ }^{29}$ plando-study-act cycles, ${ }^{5}$ statistical process control, ${ }^{30}$ and failure modes and effects analysis ${ }^{31}$ have been imported into healthcare almost wholesale.

Many of these methods may seem simple ${ }^{5}$ but are actually highly sophisticated and challenging techniques that require considerable expertise to implement well. Reviews suggest that they are not always consistently or effectively applied in healthcare. ${ }^{531}$ This might be partly because individuals and teams are not appropriately trained or experienced in the particular method. ${ }^{5}$ But more fundamentally, it points to the importance of having appropriate organisational systems, resources, and culture in place to support the systematic application of improvement methods.

One of the hidden assumptions that underpins many process improvement methods is that there are stable processes in place to improve. However, as the reliability of systems such as those for inpatient prescribing and theatre equipment availability has been found to be about $80 \%,{ }^{28}$ this can be a bold assumption. Activities in many areas of healthcare have often grown up organically over many years, so the most fundamental step in many healthcare improvement projects is often simply to design a process to begin with.
To date, the improvement approach in healthcare has largely focused on initiating large numbers of locally led improvement projects. This approach can work to optimise processes that already exist but is less suited to tackling the large, complex problems of system design. ${ }^{32}$ Again, insights from other industries are still highly relevant to healthcare, such as the importance of systems engineering.

One of the defining features of many industries is the importance of "systems integrators," who oversee and coordinate the design of complex systems. In aviation, for example, major manufacturers-such as Boeing or Airbus-fulfil this function by designing the core of the aircraft, coordinating with all the component manufacturers (from engines to flight computers), designing the maintenance processes, and defining the procedures for operating and maintaining the aircrafteven down to specifying that on certain

types of twin engine aircraft on certain types of operations, the same engineer may not conduct the same maintenance task on both engines, in case the same error is made.

Healthcare has much to learn from other industries about integrating complex technical, operational, and organisational systems. Recent examples include the systems engineering work undertaken to integrate technologies, processes, and systems in intensive care units ${ }^{334}$ and efforts to apply safety case techniques from the nuclear and chemical process industries to analyse, map, and improve the reliability of health systems. ${ }^{35}$ There are likely be new lessons to learn from developments in user-led design ${ }^{36}$ and the organisation of resilient organisational systems. ${ }^{27}$ But above all, perhaps one of the most striking and fundamental lessons for healthcare is the extent to which other industries allocate considerable resources and dedicated staff to systems analysis and quality improvement. ${ }^{24}$

\section{Box 2: Integrating systems analysis, decision making, and cognitive aids}

\section{What?}

The routine operational decisions that are made in airlines that determine whether a commercial airliner is airworthy and safe to fly are governed by a minimum equipment list (MEL).

Why?

At any point in time, any aircraft is likely to have some equipment that is faulty or inoperable. The MEL can be more than 400 pages, mapping out the conditions and contingencies under which an aircraft is safe to fly and providing the basis for sophisticated professional judgments by engineers and flight crews regarding whether an aircraft is safe to operate or not. Essentially, the MEL maps out for most conceivable scenarios that "If this is broken then it is safe to fly if A and B are operational and you don't do C."

\section{How?}

The core requirements are determined by aviation regulators, documented by aircraft manufacturers, incorporated into airline operators' procedures, and implemented by engineers and flight crew. MELs are highly systematised decision support tools that capture a deep body of technical knowledge and present it in a way that supports expert judgment and professional accountability. These sophisticated cognitive aids aim to support cautious and balanced decisions about risks: ensuring that airworthiness and safety are maintained at all times and core regulatory requirements are met, while avoiding unduly inconveniencing passengers or affecting airline revenues by removing serviceable aircraft from operation.

\section{What's different in healthcare?}

The need to balance safety and productivity pressures, and to structure shared decision making, are common to many healthcare settings, but the specifics of how such an approach might be incorporated into healthcare would need detailed analysis:

- In which healthcare contexts might it be useful to develop more extensive, systems oriented cognitive aids equivalent to a MEL, and when might such tightly structured decision making be inappropriate or overly constraining?

- How might a healthcare equivalent of a MEL be designed and implemented in surgical settings given that around $20 \%$ of surgical procedures start with missing equipment, ${ }^{28}$ and what adaptations might be required for different types of surgical procedure?

- To what extend might the principle of deep standardisation that underpins MELs conflict with new efforts to standardise healthcare processes, such as the National Safety Standard for Invasive Procedures in England, which encourages considerable variation in the local development and implementation of procedures and checklists? 


\section{From translation to exploration}

Learning from other industries is neither simple nor straightforward but it remains an important part of improving the quality and safety of healthcare. Adapting quality improvement tools from elsewhere requires a deep understanding of the mechanisms and systems that underpin an improvement technique in one industry; closely examining the context, practices, and challenges inherent in a particular setting in healthcare; and then carefully adapting and reinventing the improvement technique to work in healthcare. At the core, the process of learning from other industries is really a process of learning more about our own.

Contributors and sources: CM has researched and designed safety systems in healthcare, aviation, and other industries, including the work underpinning England's new Healthcare Safety Investigation Branch. KS has longstanding experience in systemwide quality improvement initiatives and national improvement programmes. This article arose from discussions at an international quality conference. CM drafted the article and KS reviewed and helped revise it. CM is guarantor.

Competing interests: We have read and understood BMJ policy on declaration of interests and declare that CM has previously been employed as a researcherin-residence at the Healthcare Safety Investigation Branch.

Provenance and peer review: Commissioned; externally peer reviewed.

This article is one of a series commissioned by The $B M /$ based on ideas generated by a joint editorial group with members from the Health Foundation and The BMJ, including a patient/carer. The BMJ retained full editorial control over external peer review, editing, and publication. Open access fees and The BMJ's quality improvement editor post are funded by the Health Foundation.

Carl Macrae,professor of organisational behaviour and psychology 1

Kevin Stewart, medical director ${ }^{2}$

${ }^{1}$ University of Nottingham, Nottingham University Business School, Centre for Health Innovation, Leadership and Learning, Nottingham, UK ${ }^{2}$ Healthcare Safety Investigation Branch, Farnborough, UK

Correspondence to: CMacrae carlmacrae@mac.com

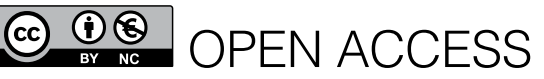

This is an Open Access article distributed in accordance with the Creative Commons Attribution Non Commercial (CC BY-NC 4.0) license, which permits others to distribute, remix, adapt, build upon this work non-commercially, and license their derivative works on different terms, provided the original work is properly cited and the use is non-commercial. See: http:// creativecommons.org/licenses/by-nc/4.0/.

\section{Check for updates}

1 Berwick DM. Continuous improvement as an ideal in health care. N Engl J Med 1989;320:53-6. doi:10.1056/NEJM198901053200110

2 Gaba DM, Howard SK, Fish KJ, Smith BE, Sowb YA. simulation-based training in anesthesia crisis resource management (ACRM): a decade of experience. Simul Gaming 2001;32:175-93. doi:10.1177/104687810103200206

3 Catchpole K, Sellers R, Goldman A, McCulloch P. Hignett S. Patient handovers within the hospital: translating knowledge from motor racing to healthcare. Qual Saf Health Care 2010;19:318-22. doi:10.1136/qshc.2009.026542

4 Lee P, Allen K, Daly M. A communication and patient safety training programme for all healthcare staff: can it make a difference? BMJ Qual Saf 2012;21:84-8. doi:10.1136/bmjqs-2011-000297

5 Reed JE, Card AJ. The problem with plan-do-study-act cycles. BMJ Qual Saf 2016;25:147-52. doi:10.1136/ bmjqs-2015-005076

6 Dixon-Woods M, Bosk CL, Aveling EL, Goeschel CA, Pronovost PJ. Explaining Michigan: developing an ex post theory of a quality improvement program. Milbank Q 2011;89:167-205. doi:10.1111/j.14680009.2011.00625.x

7 Shojania KG. The frustrating case of incidentreporting systems. Qual Saf Health Care 2008;17:400-2. doi:10.1136/qshc.2008.029496

8 Peerally MF, Carr S, Waring J, Dixon-Woods M. The problem with root cause analysis. BMJ Qual Saf 2017;26:417-22.

9 Catchpole K, Russ S. The problem with checklists. BMJ Qual Saf 2015;24:545-9. doi:10.1136/ bmjqs-2015-004431

10 Weinger MB, Hallbert BP, Logan MK. Risk and reliability in healthcare and nuclear power: learning from each other. AAMI, 2013.

11 Grote G. Safety management in different high-risk domains-all the same? Saf Sci 2012;50:1983-92. doi:10.1016/j.ssci.2011.07.017

12 Dixon-Woods M, Yeung K, Bosk CL. Why is UK medicine no longer a self-regulating profession? The role of scandals involving "bad apple" doctors. Soc Sci Med 2011;73:1452-9. doi:10.1016/j. socscimed.2011.08.031

13 Vincent C, Amalberti R. Safer healthcare: strategies for the real world. Springer, 201610.1007/978-3319-25559-0.

14 Kapur N, Parand A, Soukup T, Reader T, Sevdalis N. Aviation and healthcare: a comparative review with implications for patient safety. JRSM Open 2016;7:1 10. doi:10.1177/2054270415616548

15 Kohn LT, Corrigan JM, Donaldson MS. To err is human. Institute of Medicine, 1999.

16 Department of Health. An organisation with a memory: report of an expert group on learning from adverse events in the NHS chaired by the chief medical officer. Department of Health, 2000.

17 National Reporting and Learning System. NRLS quarterly data workbook. 2018. https:// improvement.nhs.uk/documents/2563/NaPSIR_ quarterly_data_summary_Jul_-_Sep_17.zip

18 Carrol JS. Organizational learning activities in high-hazard industries: the logics underlying self-analysis. J Manage Stud 1998;35:699-717. doi:10.1111/1467-6486.00116

19 Macrae C. The problem with incident reporting BMJ Qual Saf 2016;25:71-5. doi:10.1136/ bmjqs-2015-004732
20 National Patient Safety Foundation. RCA2: improving root cause analyses and actions to prevent harm. National Patient Safety Foundation, 2015.

21 Macrae C, Vincent C. Learning from failure: the need for independent safety investigation in healthcare. J R Soc Med 2014;107:439-43. doi:10.1177/0141076814555939

22 Wiig S, Macrae C. Introducing national healthcare safety investigation bodies. $\mathrm{Br}$ J Surg 2018;105:1710-2. doi:10.1002/bjs.11033

23 House of Lords and House of Commons Joint Committee on Draft Health Service Safety Investigations Bill. A new capability for investigating patient safety incidents. House of Commons, 2018.

24 Macrae C. Close calls: managing risk and resilience in airline flight safety management. Palgrave, 2014. doi:10.1057/9781137376121

25 Bosk CL, Dixon-Woods M, Goeschel CA, Pronovost P. Reality check for checklists. Lancet 2009;374:444-5. doi:10.1016/S0140-6736(09)61440-9

26 Goldhaber-Fiebert SN, Macrae C. Emergency manuals: how quality improvement and implementation science can enable bette perioperative management during crises. Anesthesiol Clin 2018;36:45-62. doi:10.1016/j. anclin.2017.10.003

27 Macrae C, Draycott T. Delivering high reliability in maternity care: in situ simulation as a source of organisational resilience. Saf Sci 2016 doi:10.1016/j.ssci.2016.10.019

28 Burnett S, Franklin BD, Moorthy K, Cooke MW, Vincent $\mathrm{C}$. How reliable are clinical systems in the UK NHS? A study of seven NHS organisations. BMJ Qual Saf 2012;21:466-72. doi:10.1136/ bmjqs-2011-000442

29 Radnor ZJ, Holweg M, Waring J. Lean in healthcare: the unfilled promise? Soc Sci Med 2012;74:364-71. doi:10.1016/j.socscimed.2011.02.011

30 Langley GI, Moen RD, Nolan KM, Nolan TW, Norman CL, Provost LP. The improvement guide: a practical approach to enhancing organizational performance. John Wiley, 2009.

31 Liberati EG, Peerally MF, Dixon-Woods M Learning from high risk industries may not be straightforward: a qualitative study of the hierarchy of risk controls approach in healthcare. Int J Qual Health Care 2018;30:39-43. doi:10.1093/ intahc/mzx163

32 Dixon-Woods M, McNicol S, Martin G. Ten challenges in improving quality in healthcare: lessons from the Health Foundation's programme evaluations and relevant literature. BMJ Qual Saf 2012;21:876-84. doi:10.1136/bmiqs-2011-000760

33 Nitkin K. Tomorrow's ICU. Hopkins Medicine 2017 Winter.https://www.hopkinsmedicine.org/news/ publications/hopkins_medicine_magazine/features/ winter-2017/tomorrows-icu

34 Pronovost PJ, Mathews SC, Chute CG, Rosen A. Creating a purpose-driven learning and improving health system: The Johns Hopkins Medicine quality and safety experience. Learning Health Systems 2016;1:e10018-7. doi:10.1002/lrh2.10018

35 Sujan MA, Habli I, Kelly TP, Pozzi S, Johnson CW. Should healthcare providers do safety cases? Lessons from a cross-industry review of safety case practices. Saf Sci 2016;84:181-9. doi:10.1016/j. ssci.2015.12.021

36 Von Hippel E. Democratising innovation. MIT Press, 2006.

Cite this as: BMJ 2019;364:1039

http://dx.doi.org/10.1136/bmj.l1039 